\title{
Recloning and Characterization of C2C12 Myoblast and Its Clonal Derivatives
}

\author{
Pekik Wiji Prasetyaningrum, Endah Puji Septisetyani, Ahmad Suyoko, Adi Santoso
}

Research Center for Biotechnology, Indonesian Institute of Sciences (LIPI)

\begin{abstract}
The $\mathrm{C} 2 \mathrm{C} 12$ myoblasts are adult murine muscle stem cells which isolated after injury to induce muscle regeneration. The cells are widely used in pharmaceutical and biological researches to represent skeletal muscle cells. In our laboratory, we utilize the cells for glucose uptake assay after insulin treatment and studying the muscle regeneration. In this study we conducted recloning of $\mathrm{C} 2 \mathrm{C} 12$ cells by limiting dilution cloning (LDC) and investigated the biological properties incuding cell proliferation, adhesion and differentiation of the clonal cells in comparison to the parental cells. Cell proliferation rate had been determined by WST assay, cell adhesion had been observed after cell detachment by EDTA and cell differentiation into multinucleated myotube had been investigated after induction and incubation with horse serum. As results, two clonal derivatives of $\mathrm{C} 2 \mathrm{C} 12$ myoblast cells had been retrieved by LDC and used for cell assays. Moreover, the results indicated that parental cells showed faster proliferation rate and better differentiation ability than that of clonal cells. In the contrary the parental cells exhibited weaker adhesion rate than clonal cells. To conclude, C2C12 parental cells are better for performing the glucose uptake or muscle regeneration assays since they showed better differentiation capability.
\end{abstract}

Keywords: C2C12 cells, cells differentiation, myoblast, myotube, recloning.

\section{INTRODUCTION}

The $\mathrm{C} 2 \mathrm{C} 12$ cells are mononucleated and spindle-shaped adult muscle stem cells known as satellite or myoblasts cells (Scharner and Zammit, 2011). The $\mathrm{C} 2 \mathrm{C} 12$ myoblast was originated from the line $\mathrm{C} 2$ of 2 months-old $\mathrm{C} \neg 3 \mathrm{H}$ mice primary cell cultures. Seventy hours before serial passage of myoblast, the mice muscle was treated with crush injury with a strong forceps to induce muscle regeneration (Yaffe and Saxel, 1977). The $\mathrm{C} 2 \mathrm{C} 12$ myoblasts proliferate exponentially in an appropriate growing condition at lower cell density (Tanaka, et al., 2011). On the other hands, after confluence, the cells are capable of differentiating into myocyte and multinucleated myotubes in which the process can be accelerated upon incubation with low serum condition (Cheng, et al., 2014). The myotube form of $\mathrm{C} 2 \mathrm{C} 12$ cells have been widely used in pharmaceutical and biomedical research to represent skeletal muscle cells (Magnall, et al., 1993). The studies include regulations of muscle mass development and maintenance (Murphy et al., 2016), muscle cell growth, development, and function under hormonal control (Rodgers et al., 2014) and insulin resistance

Submitted: June 13, 2021

Revised: July 14, 2021

Accepted: July 16, 2021

*Corresponding author: enda053@lipi.go.id 
and disease progression at molecular levels (Wong, 2020). In our laboratory, we use $\mathrm{C} 2 \mathrm{C} 12$ cells for glucose uptake assay, studying muscle regeneration as well as cachexia. Considering that differentiation is an important process in studies using $\mathrm{C} 2 \mathrm{C} 12$ cells, the appropriate culture condition should be considered to ensure there is no alteration of cell's phenotypes including cellular activity, cell adhesion, proliferation which could be affect to myogenic differentiation (Cornelison, 2008).

The $\mathrm{C} 2 \mathrm{C} 12$ cells should be maintained in a suitable condition in order not to lose the myoblastic features. At high cell density and at an over-confluence state, the cells may decrease their capabilities to proliferate and gradually promote differentiation into myocytes, resulting in a heterogeneous population that could affect further culture conditions during biological assays (Cornelison, 2008) (Gurdon, Lemaire and Kato, 1993). The morphological changes are observable from myoblast to more prolonged myocytes with smaller nuclei. In this study, we had performed the $\mathrm{C} 2 \mathrm{C} 12$ cells recloning to obtain the clonal derivatives and investigate their characteristics in comparison to parental cells.

\section{MATERIALS AND METHODS}

\section{Cell Culture}

The $\mathrm{C} 2 \mathrm{C} 12$ myoblast cells were obtained from Prof. Hiroshi Itoh, Nara Institute of Science and Technology (NAIST), Japan. The cells were propagated in the growth medium Dulbecco's Modified Eagle Medium (DMEM) supplemented with 15\% (V/V) Fetal Bovine Serum (Sigma, St. Louis, Missouri, USA) and 100 unit $/ \mathrm{mL}$ penicillin-100 $\mu \mathrm{g} / \mathrm{mL}$ streptomycin antibiotics (Gibco, New York, USA)in a 5\% $\mathrm{CO}_{2}$ incubator at $37^{\circ} \mathrm{C}$. The cells were maintained at lower cell density to prevent cell differentiation into myocyte.

\section{Recloning of C2C12 Cells}

The $\mathrm{C} 2 \mathrm{C} 12$ cells were recloned by limiting dilution cloning (Freshney, 2015) . The $\mathrm{C} 2 \mathrm{C} 12$ cells were harvested and seeded at a density of 10 cells/ $\mathrm{mL}$ onto a 96 well plate. The plate was incubated for several days in the incubator until the growing clones could be observed. Furthermore, the single clones were selected and supplemented with fresh medium. Cells incubation was continued until day 8 post-seeding. The selected single clonal population showing different cell morphologies were scaled up onto $6 \mathrm{~cm}$ culture dishes and used for further in vitro assays.

\section{Cell Proliferation Assay}

Cell proliferation was measured by using Water Soluble Tetrazolium salt (WST) assay (Roche, Basel, Swiss). First, the C2C12 cells were seeded at the density of 4,000 and 10,000 cells per well onto 96-well plates. The cells growth rate was then investigated after 18, 42, 66 and $90 \mathrm{~h}$ incubation, respectively. At the end of incubation, WST assay was performed according to the manufacturer's protocol. The relative cell growths were calculated by dividing the normalized absorbance measured at 42,66 , or $90 \mathrm{~h}$ incubation with the normalized absorbance measured at $18 \mathrm{~h}$ incubation. Each treatment was performed in triplicate.

\section{Differentiation Assay}

The parental $\mathrm{C} 2 \mathrm{C} 12$ and its clonal derivatives were seeded at a density of 75,000 cells/ $\mathrm{mL}$ in a 6 well plate in the growth medium. Two days after seeding (D0), the medium was replaced by differentiation medium containing $2 \%$ horse serum/DMEM. The differentiation medium was periodically replaced with fresh medium every 2 days. The myotube formation was observed after 6 days incubation in differentiation medium (D6). The cells were fixed and stained using $1 \%$ crystal violet and observed using a microscope to analyze the differentiation and fusion index (Yang, et al., 2013) (Septisetyani, et al., 2021).

\section{Cell Adhesion Assay}

The $\mathrm{C} 2 \mathrm{C} 12$ parental and clonal cells were harvested by using $10 \mathrm{mM}$ EDTA. To each $10 \mathrm{~cm}$ 
A

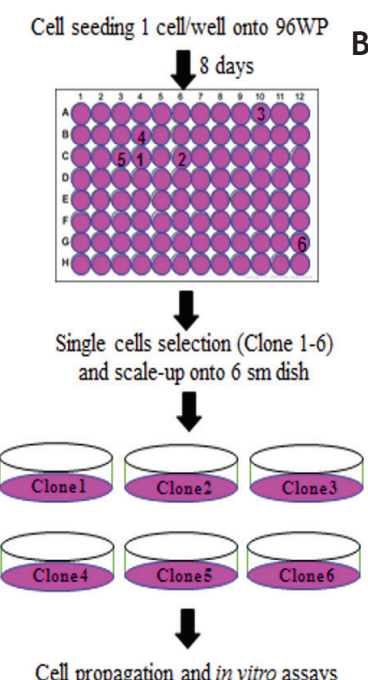

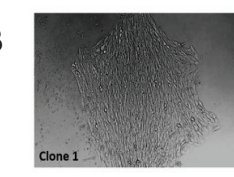

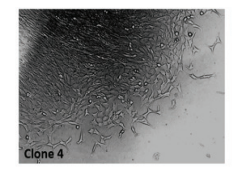

C
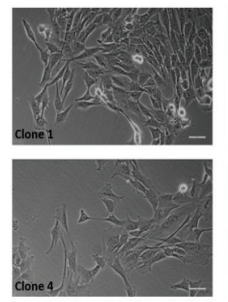
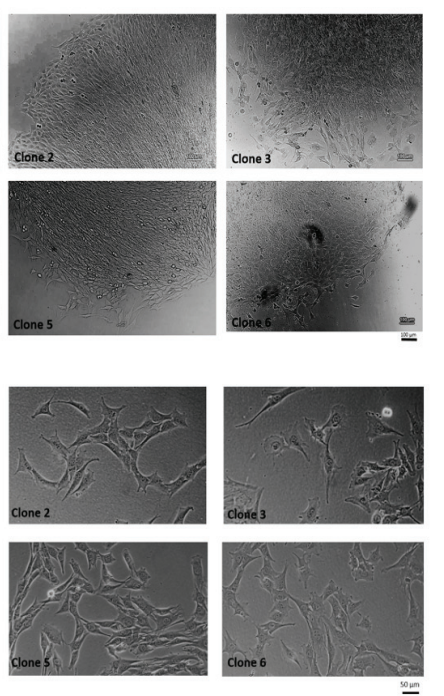

Figure 1. Recloning of $\mathrm{C} 2 \mathrm{C} 12$ cells. A. Schematic representative of limiting dilution cloning and retrieval of single clones. B. Images of six clones which were retrieved for further cell propagation. C. The morphology of the clonal cells after cell propagation in $6 \mathrm{~cm}$ culture dishes.

culture dish, about $2 \mathrm{~mL}$ of EDTA solution was added after two times washing with PBS. EDTA solution was then aspirated, leaving a thin layer of the solution to cover the cells. Then, the cells were incubated for 5 minutes in $\mathrm{CO}_{2}$ incubator. The cells were seeded at a density of 300,000 cells $/ \mathrm{mL}$ in 96 well plate and the cells attachment was investigated after $2 \mathrm{~h}$ incubation.

(A)

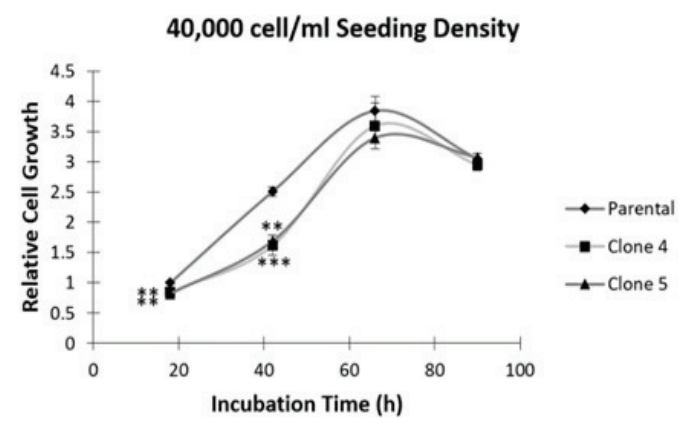

\section{RESULTS}

\section{Recloning of $\mathrm{C} 2 \mathrm{C} 12$ Cells}

The $\mathrm{C} 2 \mathrm{C} 12$ parental cells had been recloned by using limiting dilution method to obtain the clonal derivatives. Eight days after cloning, six populations of single clone were retrieved and propagated into $6 \mathrm{~cm}$ culture dishes. The clonal

(B)

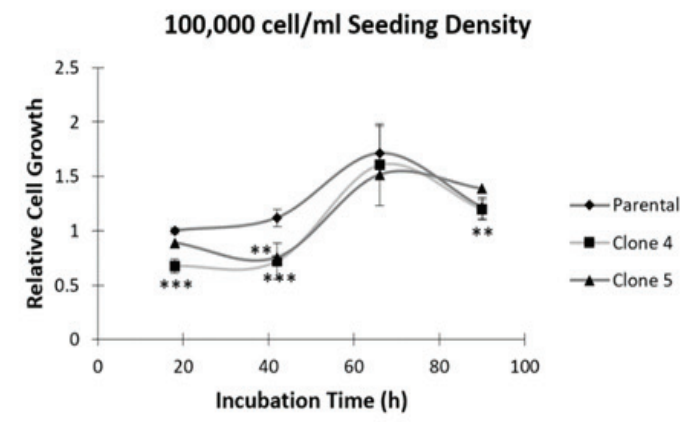

Figure 2. Proliferation rate of parental and clonal $\mathrm{C} 2 \mathrm{C} 12$ cells at different seeding densities as indicated in the graphs. Cell viability after $18,42,66$, and $90 \mathrm{~h}$ incubation were determined by using WST assay. The relative cell growth was quantified to analyze the cells proliferation rate. Bars indicated SD of data in triplicate. 

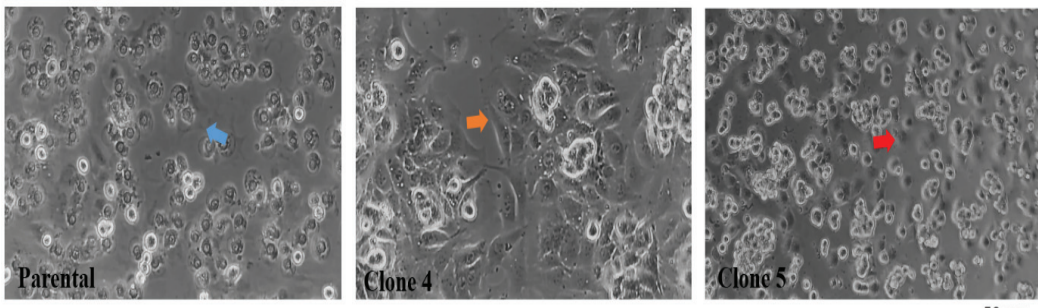

Figure 3. Representative images of parental and clonal C2C12 cells adhesion two $h$ after seeding. The cells were harvested by using EDTA and seeded at 300,000 cells/mL density onto a 96 well plate. Blue arrow indicates round cell with weak adhesion state; red arrow indicates cell with intermediate state of adhesion; orange arrow indicates cell with higher adhesion state.

cells showed distinct proliferation rate. Among six clones, clone 4 and 5 exhibited the fastest cell growth and picked up for further assays, including proliferation, adhesion, and differentiation assays.

\section{The C2C12 Cells Proliferation Rate}

Relative cell growth was observed to analyze the proliferation rate of parental $\mathrm{C} 2 \mathrm{C} 12$ and its clonal derivative cells. The results showed that different initial seeding density influences the growth kinetics of both parental and clonal cells. At 40,000 cell $/ \mathrm{mL}$ seeding density, all parental and clonal cells proliferated exponentially, with parental cells showed higher proliferation rate, and reached a peak at 66 hours incubation. On the other hand, at 100,000 cell $/ \mathrm{mL}$ seeding density, cells might enter stationary phase and grew more slowly. In conclusion, at two different seeding densities, the parental cells exhibited higher proliferation rate compared to both clone 4 and 5 .

\section{Cell Adhesion}

The $\mathrm{C} 2 \mathrm{C} 12$ cells are adherent cells which grow by attaching to the culture vessel. The interaction of cell with culture vessel, which had been coated with extracellular matrix (ECM) mimics material, is an initial step that could affect to cellular activity as well as cell communication, proliferation and differentiation (Černochová, et al., 2020). In this study, the cell initial attachment rate

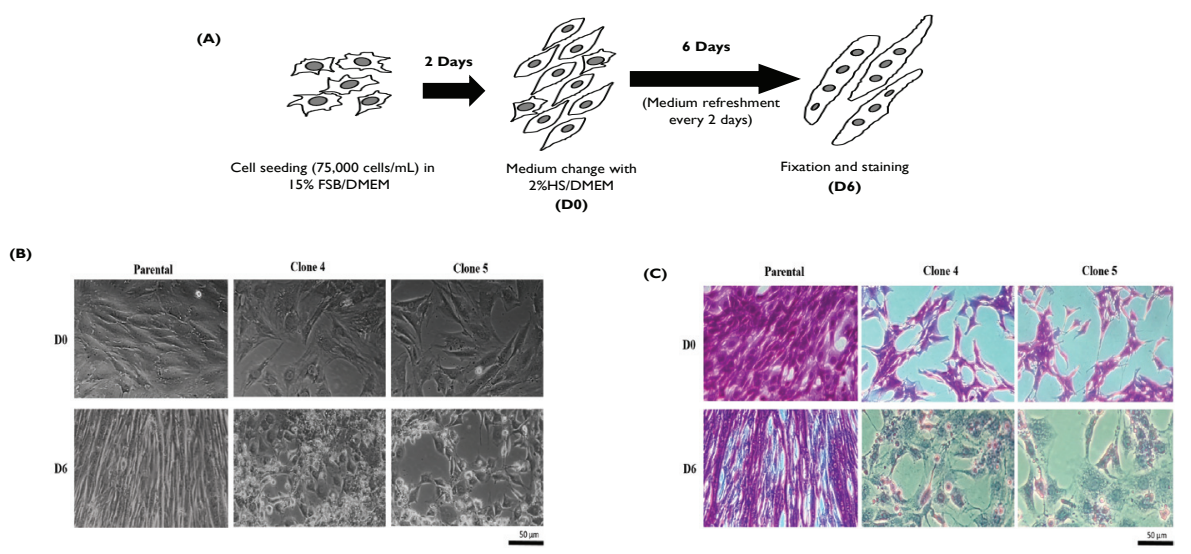

Figure 4. Representative images showing the parental and clonal C2C12 cells after differentiation induction. A. Schematic representation of $\mathrm{C} 2 \mathrm{C} 12$ differentiation into multinucleated myotubes. B. Phasecontrast micrographs of parental and clonal cells at D0 and D6. C. Representative crystal violet staining images of parental and clonal cells at D0 and D6. 
A

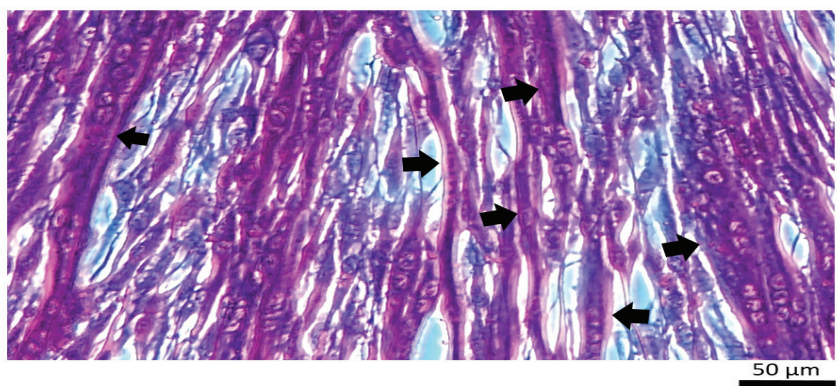

B

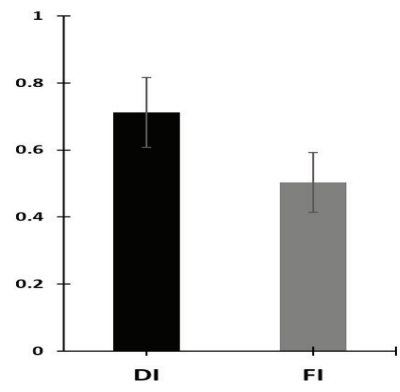

Figure 5. Quantification of differentiation (FI) and fusion index (FI). A. Representative image of multinucleated myotubes formed in $\mathrm{C} 2 \mathrm{C} 12$ parental cells. Arrows indicate the multinucleated myotubes. $\mathrm{B}$. The differentiation state of parental cells at D6 which was represented by DI and FI. The crystal violet staining was used to visualize the multinucleated cells to calculate the DI and FI.

of the clonal cells was investigated in comparison to the parental $\mathrm{C} 2 \mathrm{C} 12$ cell. The cells were harvested by EDTA without trypsin to maintain position of adhesion receptors in the cell membrane (Huang, et al., 2010) (Schubert, et al., 2014). The result exhibits that clone 4 had adhered better in the culture vessel within $2 \mathrm{~h}$ post seeding in comparison to parental and clone 5 cells.

\section{Investigation of Cell Differentiation}

The ability of parental and clonal $\mathrm{C} 2 \mathrm{C} 12$ cells to differentiate into myotubes were observed. The result showed that myotube structures were only formed in parental cells which had been observed well either in unstained or stained cells. In contrast, the clonal cell did not show the formation of myotubes. This phenomenon might occur because of the different level of cell densities two days post seeding when the time of the differentiation induction had been started (Figure 4). In addition, the differentiation state of parental cells was defined by the value of differentiation index (DI) and fusion index which (FI) represented by $0.712 \pm 0.104$ for DI and $0.504 \pm 0.089$ for FI (Figure 5).

\section{DISCUSSION}

The $\mathrm{C} 2 \mathrm{C} 12$ cells should be maintained properly to preserve the myoblastic properties and myogenesis capabilities for their application in pharmaceutical and biological researches. The optimization of cell growth condition is a primary step to do in relation to the heterogeneity of the cell population. In this study, we conducted recloning process to investigate the cellular properties of the clonal cells related to myogenesis including initial adhesion, proliferation and differentiation in comparison to the parental cell. The recloning process was performed by limiting dilution cloning (LDC) which is economical and easy to be performed (Priola, et al., 2016). From six single clones which had been isolated and observed with different cell morphologies, clone 4 and 5 showed higher proliferation rate than other clones and applied for the next examination.

Cellular adhesion in important in affecting cell migration and proliferation (Acharya and Yap, 2016). For adherent cells, different strength of cell adhesion to the culture vessel may contribute to different cell spreading morphologies (Martín-pardillos, et al., 2019). Thus, the clonal derivatives and the parental cells might show different adhesion strength due to their different cell morphologies. Here, we observed initial cell adhesion capability in two $\mathrm{h}$ after cell seeding. Interestingly, clone 4 cells showed better cell spreading, followed by clone 5 , which represents better cell adhesion. Meanwhile parental cells showed less spreading morphology indicating weaker cell adhesion. These phenomena might be 
implicated in their difference on cell proliferation wheretheparental cellswith weakeradhesion showed higher proliferation rate (Černochová, et al., 2020. The parental cells consist of more heterogenous cell population than the clonal derivatives which may contribute to the difference of initial cell attachment and spreading (Martín-pardillos, et al., 2019).

The proliferation assay of the $\mathrm{C} 2 \mathrm{C} 12$ parental and single clonal derivatives had been conducted in two different seeding conditions. Lower cell seeding density promoted higher proliferation rate than higher cell seeding density. At higher cell density, intercellular communication via gap junctions results in the contact-inhibition of cell division. Furthermore, less nutrients and hypoxia occur faster in more crowded cells (Zhou, et al., 2011).

Both cell adhesion and proliferation have been implicated in myogenesis. Eventhough proliferating cells possess contradictory cellular properties to the differentiating cells, however, cell proliferation support higher cell number or density as one of prerequisites of myogenesis. During differentiation assay in this study, only parental cells reached appropriate cell density to undergo cell differentiation whereas the clonal cells failed to differentiate (Figure 4). As mentioned in the previous section, proliferation rate of the parental cells was highest among the cells tested. Once the cells reach higher confluence, cell cycle negative regulators such as decorin, cyclin D3, and CDKI p21 and differentiation markers such as $\mathrm{MyoD}$ and myogenin will be upregulated (Tanaka, et al., 2011). In addition, cell adhesion and density will affect cellcell fusion to form multinucleated myotubes. Upon differentiation, $\mathrm{C} 2 \mathrm{C} 12$ cells form syncytia which represent strong intercellular adhesion which promotes fusion (Tachibana and Hemler, 1999)

The $\mathrm{C} 2 \mathrm{C} 12$ cells will differentiate into myocytes and gradually form myotubes once they reach confluence. At this condition, the proliferative activity of the cells will eventually decrease, which affects the cell growth on the daily culture basis. Our parental cells showed distinct myogenic properties than that of the clonal cells which indicated that heterogeneity of cell population exist in the parental cells. However, this parental cell population possesses better myogenic properties than homogenous cell population of the clonal cells. Furthermore, to preserve the myoblastic properties of parental $\mathrm{C} 2 \mathrm{C} 12$ cells, appropriate cell culturing condition by maintaining cells at lower densities is recommended to keep $\mathrm{C} 2 \mathrm{C} 12$ cells' myoblastic properties. (Tanaka, et al., 2011). Based on this study, we obtained information that the heterogeneity of parental cell affected the cell proliferation rate and cell adhesion which are important to maintain the cell myoblastic properties and capability to undergo the myogenesis.

\section{CONCLUSION}

Two clonal derivatives of $\mathrm{C} 2 \mathrm{C} 12$ myoblast cells which had been retrieved in this study showed different phenotypes from the parental cells. The clonal cells exhibited faster cell adhesion and spreading after cell detachment by EDTA. Meanwhile, parental cells showed higher proliferation rate and better differentiation ability than that of clonal cells.

\section{ACKNOWLEDGMENT}

This research had been financially supported by Indonesian Ministry of Research and Technology/BRIN/LPDP 2020 (grant No. 91/E1/ PRN/2020) to EPS.

\section{REFERENCES}

Acharya, B.R. and Yap, A.S., 2016, Cell-Cell Adhesion and the Cytoskeleton, Encyclopedia of Cell Biology, 2, 704-712.

Černochová, P., Blahová, L., Medalová, J., Necas, D., Michlicek, M., Kaushik, P., et al., 2020, Cell type specific adhesion to surfaces functionalised by amine plasma polymers, Sci. Rep., 10, 9357. 
Indonesian Journal of Cancer Chemoprevention, June 2021 ISSN: 2088-0197

e-ISSN: $2355-8989$

Cheng, C.S., El-Abd, Y., Bui, K., Hyun, Y-E., Hughes, R.H., Kraus, W.E., et al., 2014, Conditions that promote primary human skeletal myoblast culture and muscle differentiation in vitro, $A m \mathrm{~J}$ Physiol Cell Physiol, 306(4), C385-C395.

Cornelison, D., 2008, Context matters: In vivo and in vitro influences on muscle satellite cell activity, J. Cell. Biochem., 105(3), 663-669.

Freshney, R.I., 2015, Culture of animal cells: a manual of basic technique and specialized applications, $7^{\text {th }}$ ed, John Wiley \& Sons.

Gurdon, J.B., Lemaire, P. and Kato, K., 1993, Community Effects and Related Phenomena in Development, Cell, 75(5), 831-834.

Huang, H.L., Hsing, H.W., Lai, T.C., Chen, Y.W., Lee. T.R., Chan, H.T., et al., 2010, Trypsin-induced proteome alteration during cell subculture in mammalian cells, J. Biomed. Sci, 17(1), 1-10.

Mangnall, D., Bruce, C. and Fraser, R.B., 1993, Insulin-stimulated glucose uptake in $\mathrm{C} 2 \mathrm{C} 12$ myoblasts, Biochem Soc Trans, 21(4), 438S.

Martín-Pardilos, A., Chiva, Á.V., Vargas, G.B., Blanco, P.H., Cid, R.P., et al., 2019, The role of clonal communication and heterogeneity in breast cancer, BMC Cancer, 19, 666.

Murphy, S.M., Kiely, M., Jakeman, P.M., Kiely, P.A. and Carson, B.P., 2016, Optimization of an in vitro bioassay to monitor growth and formation of myotubes in real time, Biosci Rep., 36(3), e00330.

Priola, J.J., Calzadilla, N., Baumann, M., Borth, N., Tate, C.G. and Betenbaugh, M.J., 2016, Highthroughput screening and selection of mammalian cells for enhanced protein production, Biotechnology Journal, 11(7), 853-865.

Rodgers, B.D., Wiedeback, B.D., Hoversten, K.E., Jackson, M.F., Walker, R.G. and Thompson, T. B., 2014, Myostatin stimulates, not inihibits, C2C12 myoblast proliferation, Endocrinology, 155(3), 670-675.

Scharner, J. and Zammit, P. S., 2011, The muscle sat- ellite cell at 50: the formative years, Skeletal Muscle, 1(1), 28.

Schubert, R., Strohmeyer, N., Bharadwaj, M., Ramanathan, S.P., et al., 2014, Assay for characterizing the recovery of vertebrate cells for adhesion measurements by single-cell force spectroscopy, FEBS letters, 588(19), 3639-3648.

Septisetyani, E.P., Prasetyaningrun, P.W. and Santoso A., 2021, Naringin May Alleviate Doxorubicin Cytotoxic Effects In C2C12 Myoblastcells, IOP Conference Series: Earth and Environmental Science, 762(1), 012027.

Tachibana, I. and Hemler, M.E., 1999, Role of transmembrane 4 superfamily (TM4SF) proteins CD9 and CD81 in muscle cell fusion and myotube maintenance, J Cell Biol, 146(4), 893-904.

Tanaka, K., Sato, K., Yoshida, T., Fukuda, T., Hanamura K., et al., 2011, Evidence for cell density affecting C2C12 myogenesis: possible regulation of myogenesis by cell-cell communication, Muscle Nerve, 44(6), 968-77.

Wong, C.Y., Al-Salami, H. and Dass, C.R., 2020, C2C12 cell model: its role in understanding of insulin resistance at the molecular level and pharmaceutical development at the preclinical stage, Journal of Pharmacy and Pharmacology, 72(12), 1667-1693.

Yaffe, D. and Saxel, O., 1997, Serial Passaging and Differentiation of Myogenic Cells Isolated from Dystrophic Mouse Muscle, Nature, 270, 725-727.

Yang, M., Wei, D., Mo, C., Zhang, J., Wang, X., Han, X., et al., 2013, Saturated fatty acid palmitate-induced insulin resistance is accompanied with myotube loss and the impaired expression of health benefit myokine genes in C2C12 myotubes, Lipids in Health and Disease., 12, 104.

Zhou, H., Weir, M.D. and Xu, H.H., 2011, Effect of cell seeding density on proliferation and osteodifferentiation of umbilical cord stem cells on calcium phosphate cement-fiber scaffold, Tissue Engineering Part A, 17(21-22), 2603-2613. 